\title{
Penyebab dan Resistensi Kegalauan pada Remaja Pacaran (Studi Kasus di Desa Pandan Indah Kabupaten Lombok Tengah)
}

\author{
Rohimi \\ Interdisciplinari Islamic Studies (IIS) UIN Sunan Kalijaga Yogyakarta \\ Email: dinobastian11@gmail.com
}

\begin{abstract}
Dating has become a part of social phenomena in society. Dating is indeed a way to strengthen the closeness between men and women. But in dating, it is not always smooth, but someone can experience breakups, fights, and so on. Therefore. This study examines the causes and resistance of anxiety in dating adolescents who experience a breakup or fight with their partners. This research was conducted in Pandan Indah Village, Praya Barat Daya District, Central Lombok Regency, using a qualitative approach or field research. The data collection methods used in this study were interviews, documentation and observation, with the aim of knowing the causes and resistance of anxiety in dating adolescents in Pandan Indah Village, Praya Barat Daya District, Central Lombok Regency. The results and discussion in this study are. First, the phenomenon of the teenage dating culture in Pandan Indah Village which is still thick or fanatical with their dating culture, namely midang, where midang is the arrival of a man to his girlfriend's house which is only carried out at night with certain purposes such as strengthening his relationship, building solidarity or closeness. the families of both parties, then to discuss their future wedding day. Second, the causes of turmoil in dating relationships in Pandan Indah Village include dishonest couples, lack of communication and cheating partners. Third, the resistance of turmoil in dating relationships in Pandan Indah Village, namely such as calming down in the room, doing spirituality such as reciting and praying, and calming their gala feelings by listening to music.
\end{abstract}

Keywords: Causes, Confusion Resistance and Dating Adolescents.

\begin{abstract}
Abstrak
Pacaran memang sudah menjadi bagian dari fenomena sosial dalam masyarakat. Pacaran memang sebagai jalan untuk mempererat kedekatan antara laki-laki dan perempuan. Namun dalam pacaran, tidak selamanya mulus, melainkan seseorang dapat mengalami putus cinta, berantam, dan lain sebagainya. Oleh sebab itu. penelitian ini mengkaji tentang penyebab dan resistensi kegalauan remaja pacaran yang mengalami putus cinta ataupun berantam dengan pasangannya. Penelitian ini dilakukan di Desa
\end{abstract}




\section{6 | TAZKIR: Jurnal Penelitian Ilmu-ilmu Sosial dan Keislaman}

Vol. 07 No. 2 Desember 2021

Pandan Indah Kecamatan Praya Barat Daya Kabupaten Lombok Tengah, dengan pendekatan kualitatif atau penelitian lapangan. Metode pengumpulan data yang dilakukan dalam penelitian ini yakni wawancara, dokumentasi dan observasi, dengan tujuan untuk mengetahui penyebab dan resistensi kegalauan pada remaja pacaran di Desa Pandan Indah Kecamatan Praya Barat Daya Kabupaten Lombok Tengah. Hasil dan pembahasan dalam penelitian ini yakni. Pertama, fenomena budaya pacaran remaja di Desa Pandan Indah yang masih kental atau fanatis dengan buday pacarannya yakni midang, di mana midang merupakan kedatangan seorang laki-laki ke rumah pacaranya yang hanya dilaksanakan pada malam hari dengan tujuan tertentu seperti menguatkan hubungannya, membangun solidaritas atau kedekatan keluarga kedua belah pihak, kemudian untuk membicarakan hari pernikahan mereka kedepannya. Kedua, penyebab kegalauan dalam hubungan pacaran remaja di Desa Pandan Indah yakni seperti pasangan yang tidak jujur, kurang komunikasi dan pasangan yang selingkuh. Ketiga, resistensi kegalauan dalam hubungan pacaran remaja di Desa Pandan Indah yakni seperti menenangkan diri di dalam kamar, melakukan spiritualitas seperti mengaji dan sholat, serta menenangkan perasaan galaunya dengan mendengar musik.

Kata Kunci: Penyebab, Resistensi Kegalauan dan Remaja Pacaran.

\section{PENDAHULUAN}

Pacaran sebagai terminologi atau istilah dua orang yang sedang menjalankan hubungan yang dilandasi dengan perasaan cinta. Pacaran memang dapat dijumpai dari kalangan muda-mudi seperti remaja dan dewasa. Menurut Akhbar, kisaran usia remaja pacaran tersebut dapat ditandai pada usianya yang sudah memasuki usia 18-20an tahun (Lubis, hlm. 102). Oleh karena itu, pacaran ini adalah sebuah entitas dari apa yang sedang dirasakan oleh seseorang yang tentunya adanya dorongan ketertarikan dan proses interaksi yang disandingi dengan adanya perhatian dan pengertian yang lebih pada pasangannya (Feist dkk., 2017, hlm. 87-89).

Perilaku yang sangat mendasari jiwa afeksi itu tidak jauh berdampak kepada bentuk kepedulian semata dan membangun hubungan yang disebut dengan pacaran (Ariyati \& nuqul, 2016, hlm. 30). Namun, di sisi lain kita melihat hubungan pacaran pada anak remaja memang akan kelihatan lebih ke trend sosial (social trend) dan lebih masif, terlebih-lebih di Era saat ini. Sehingga dengan perasaannya akan menunjukkan kesetiaan dan ingin melakukan segala hal 
hanya untuk mempertahankan hubungannya semata (Indriastuti \& nawangsari, 2014, hlm. 155).

Menurut Putri, bentuk komitmen (commitment) dalam hubungan pacaran adalah tanda hasratnya yang ingin terus menjalankan suatu hubungan sampai ke tahap yang lebih serius yakni menikah (Angelia, hlm, 10-12). Menurut Atmoko, hubungan pacaran didasari dengan tiga hal penting bahkan signifikan yakni untuk mengetahui siapa pendamping hidupnya, proses ketertarikan pada lawan jenisnya, dan sebagai teman hidup yang dijalani sejak dari sekarang sudah begitu intensif untuk berduaan (Imaningtyas dkk., 2017, hlm. 168). Sehingga kata pacaran itu adalah sebagai bukti kebersamaannya, sedangkan pacar berarti orang yang sangat ia cintai dan sangat spesial dalam hidupnya (Imaningtyas dkk., 2017, hlm. 169-170).

Namun dalam menjalankan hubungan pacaran sangat lebih baik jika sudah dijalankan pada tahap dewasa (Gunarsa, 2004, hlm. 51). Karena semakin dewasa seseorang maka semakin baik dan matang pula pola pikirnya untuk menjalani sebuah hubungan pacaran, terlebih-lebih banyak kita lihat bahwasannya, pacaran sangat mempengaruhi beberapa faktor seperti hubungan intim (erotism) maupun pergaulan bebas (pettings) (Triana dewi, 2020, hlm. 47-50). Jess juga berpendapat, bahwasannya ketertarikan seseorang yang menggeluti dirinya dalam hal pergaulan bebas, minuman keras, sedih, murung dalam kamar, dan depressi dalam hidup yakni mereka yang disebabkan oleh adanya retak batin atau timbulnya perasaan yang terluka (Feist dkk., 2017, hlm. 72-73).

Dari hal ini, begitu pentingnya bahwasaanya untuk menjalankan hubungan pacaran adalah hal yang kelihatan simple tapi jika terjadi masalah diantara keduanya akan menyebabkan hal yang serius dalam batin yang juga akan mempengaruhi kepribadiannya. Adanya kesalahan dalam membina hubungan pacaran juga akan berdampak kepada perilaku individu yang cenderung tidak normal dalam hal batin ataupun pikirannya seperti depressi atau stress, melakukan perilaku buruk minuman keras dan lain sebagainya yang berkenaan dengan membahayakan dirinya sendiri (Feist dkk., 2017, hlm. 73). Di mana tingkat kesedihan yang dirasakan akan menyebab pribadinya akan buruk, putus cinta bisa menghadirkan adanya rasa sedih (Christianti, hlm 27-29).

Oleh karena itu, tujuan dalam penelitian ini yakni untuk mengetahui akan bagaimana penyebab dan resistensi remaja pacaran di Desa Pandan Indah Kecamatan Praya Barat Daya Kabupaten Lombok Tengah. Dari hasil analisis 


\section{8 | TAZKIR: Jurnal Penelitian Ilmu-ilmu Sosial dan Keislaman}

Vol. 07 No. 2 Desember 2021

peneliti, bahwasannya penyebab putus cinta dalam hubungan pacaran remaja pacaran di Desa Pandan Indah ini cenderung beragam (fariative). Dampak putus cinta juga berimbas kepada kepribadianya. Sehinga pentingnya resistensi diri seorang remaja yang pacaran agar mampu mengendalikan dirinya serta tidak memperburuk pribadinya hanya dengan perasaannya yang hancur akibat hubungan pacarannya yang tidak stabil lagi mereka rasakan.

Karena putus cinta adalah hal yang serius dalam mengubah kondisi hati juga perilaku individu. Seperti halnya, ketika remaja pacaran di Desa Pandan Indah mengalami putus cinta atau berantam dengan pasangannya, maka ia akan cenderung untuk melakukan hal-hal buruk seperti minum-minuman keras, dengan tujuan untuk menghilangkan rasa sakit hatinya, mengurung diri dalma kamar, sedih, bahkan stress. Selain itu ada juga yang menangis hal ini biasanya yang terjadi pada remaja perempuan. Meski ada beberapa yang baik bersifat spiritual, namun hal itu tidak lain semata-mata demi menghilankan rasa sakit hati yang telah dirasakan akibat putus cinta.

\section{METODE PENELITIAN}

Penelitian ini menggunakan penelitian lapangan (field research) dengan metode pengumpulan data yakni wawancara, dokumentasi dan observasi. Tujuan dalam penelitian ini yakni tentunya untuk mengetahui bagaimana penyebab dan resistensi atau resolusi secara personal para remaja yang mengalami putus cinta dengan pasanganya di Desa Pandan Indah Kecamatan Praya Barat Daya Kabupaten Lombok Tengah. Karena putus cinta juga kadang berdampak dalam membahayakan diri orang yang berpacaran, terlebih-lebih mereka yang masih ditahap remaja. Oleh karena itu, peneliti dapat mereduksi data dengan cara pengumpulan data terlebih dahulu lalu dilakukan codings untuk mencari poin yang relevan dari hasil responden saatmelakukan wawancara.

\section{HASIL DAN PEMBAHASAN}

\section{Sekilas Tentang Desa Pandan Indah Kecamatan Praya Barat Daya Kabupaten Lombok Tengah}

Desa Pandan Indah merupakan salah satu desa yang berada di wilayah Kecamatan Praya Barat Daya Kabupaten Lombok Tengah, di mana Desa Pandan Indah merupakan pecahan dari Desa Kabul yang mekar sekitaran tahun 2004 
yang dipimpin oleh bapak Abd. Rahim, S.Ag sebagai kepala Desa Pandan Indah perdana. Pemekaran ini terjadi dilandasi dengan adanya inisiasi dari masyarakat Desa Pandan Indah sendiri, mengingat pusat pemerintahan desa atau kantor desa yang terletak di Desa Kabul sangatlah jauh dan membuat masyaraat kesulitan untuk mengurus kepentingannya di desa.

Kata Pandan Indah Diambil dari nama sebuah tempat dimana kantor desa dibangun ditengah pohon pandan yang tinggi dan dipandang sangat indah. Namun lebih dari itu bahwa nilai filosofis dari pohon pandan tersebut diharapkan sebagai motivasi bagi siapa saja yang memimpin desa Pandan Indah. Nilai filosofis yang dimaksud adalah bahwa pohon pandan adalah multi fungsi tidak ada bagian yang sia-sia akan tetapi semua mempunyai mampaat yang luar biasa diantaranya yaitu: daun nya bisa dipakai sebagai tikar yang sangat nyaman, tas, lompak (tempat rokok) dan lain sebagainya.

Desa Pandan Indah Kecamatan Praya Barat Daya di himpit oleh Desa Bonder di bagian timur, Desa Kabul dibagian barat Desa Mangkung di bagian selatan dan Desa Setanggor di bagian utara. Secara administrasi Desa Pandan Indah Kecamatan Praya Barat Daya Desa Pandan Indah terbagi dalam 11 dusun, dengan luas wilayah \pm 734.79 hektar. Desa Pandan Indah juga diintensifikasi dengan lahan yang didominasi dengan persawahan atau pertanian seluas 420,79 Ha. Setelah itu lahan Desa Pandan Indah juga disertai dengan perkebunan, pemukiman dan lain sebagainya. Sedangkan dalam sistim strukut mata pencaharia masyarkat Desa Pandan Indah juga sangat di dominasi dengan petani sebanyak $79 \%$. Ini menunjukkan representasi, bahwa petani menjadi bentuk bagian pekerjaan masyarakat Desa Pandan Indah yang sangat mendominasi (Dokumentasi Desa Pandan Indah Kecamatan Peraya Barat Daya Kabupaten Lombok Tengah (01 Desember 2021, Jam 12.12 Wita).

\section{Budaya Pacaran Di Desa Pandan Indah Kecamatan Praya Barat Daya Kabupaten Lombok Tengah}

Dengan masih begitu konvensional atau Desa Pandan Indah termasuk bagian desa yang berada di daerah pinggiran atau jauh dari perkotaan. Sehingga budaya pacaran di Desa Pandan Indah masih fanatisme dengan sebutan midang. Midang merupakan budaya pacaran di sebagian besar masyarakat Lombok khususnya budaya midang ini juga masih kental terjadi atau masih dilakoni oleh para pujangga di Desa Panda Indah. 
Budaya midang merupakan sebutan untuk para laki-laki yang berkunjung ke rumah pacarnya yang hanya dilakukan pada malam hari saja setelah waktu magrib sampai jam 9 (sembilan) malam. Midang ini bertujuan untuk menguatkan cinta seseorang pemuda dengan pacarnya, menguatkan kedekatan si pemuda dengan orang tua atau keluarga si cewek dan membicarakan kapan hari pernikahan mereka akan dilakukan. Menurut Hamsun, midang juga sebagai strategi untuk menguatkan hubungan ke dua belah pihak secara bilateral, ukan saja pada hubungan pacaran si anaknya, namun juga berimbas kepada hubungan keluarga (Yakub, Hlm 90).

Oleh karena itu, midang salah satu budaya pacaran yang masih dilestarikan oleh anak muda di Desa Pandan Indah. Bahkan pada saat pergi midang, pemuda hendak membawakan makanan untuk pacaranya seperti jajan, minuman dan lain sebagainya. Sehingga midang ini menuai maksud bukan sekedar datang biasa seorang laki-laki ke rumah perempuan yang dianggap sebagai kekasih hatinya (parman, 1995, hlm. 8). Midang adalah cara atau prosesi pacaran anak remaja ataupun dewasa di Desa Pandan Indah. Midang masih dilakukan hingga saat ini dan menjadikan midang sebagai benang merah dalam menuju hubungan pernikahan atau merarik.

\section{Penyebab Kegalauan Remaja Pacaran Di Desa Pandan Indah Kecamatan Praya Barat Daya Kabupaten Lombok Tengah}

Pacaran merupakan sebutan bagi seseorang yang sedang berada di level kasmaran. Pacar akan menjadi seseorang yang akan sangat diberikan perhatian lebih dari sekedar teman. Oleh karena itu, pacaran berarti kondisi dua insan yang sedang menebar kasih sayang.(Arisandi, 2015, hlm. 68) Namun pacaran tidak selamanya bisa memberikan ruang kebahagiaan semata, bahkan bisa memicu pelbagai kendala yang menyebabkan atau berimbas kepada sisi internal masing-masing individu. Misalnya pacaran akan memicu kesan sedih jika tidak sesuai ekspektasi dalam membina hubungannya.

Sedangkan menurut Efendi, perihal pacaran di masa remaja adalah bentuk pacaran yang belum stabilitas. Masa remaja masih berada di bawah masa dewasa yang di mana secara pemikirannya masih belum matang, sehingga jika terjadinya kekacauan dalam hubungan pacarannya, maka akan cenderung cepat mengalami hal-hal negatif maupun cepat stress, sedih atau galau.(efendi, 2018, hlm. 290) 
Remaja pacaran di Desa Pandan Indah juga demikian, ketika menjalani sebuah hubungan pacaran senantiasa akan menjadi hal yang membuatnya bahagia, namun di sisi lain akan merasakan sedih ketika menuai beberapa faktor yang menyebabkan perasaannya hancur akibat putus cinta dengan pasangannya. Di sini ada beberapa penyebab kegalauan atau yang cenderung terjadi atau dialami oleh remaja pacaran di Desa Pandan Indah Kecamatan Praya Barat Daya Kabupaten Lombok Tengah jika mengalami putus cinta yakni :

\section{Pasangan Yang Tidak Jujur}

Pasangan yang tidak jujur adalah penyebab terjadinya hubungan yang tidak harmonis. Kejujuran atau jujur dalam perspketif Islam berarti berakhlak dan menunjukkan kepribadiannya yang positif. Jujur berarti menyampaikan apa yang dapat dipercaya dan tidak berdusata, begitu juga dengan menjaga hubungan pacaran atau perasaan. Dengan kejujuran akan membuat pasangan akan menjadi nyaman, tapi jika menuai kebohongan dan tidak jujur maka akan menyebabkan pertengkaran dan hal yang menyebabkan hubungan pacaran menjadi kandas.

Seperti paparan responden di bawah ini mengenai kejujuran seorang pasangan atau perihal kejujuran dalam hubungan pacarannya.

"Karena sifat bohong atau ketidakjujuran pada pasangan saya adalah salah satu sifat yang sangat saya tidaksukai. Lantas, karena kesetiaan atau komitmen menurut saya adalah keharusan dalam membangun perasaan dan hubungan dalam berpacaran, sehingga jika pasangan saya melakukan sifat ketidakjujuran atau suka berbohong, tentu akan menurunkan rasa emosional perasaan saya bahkan saya akan membangun rasa benci saya pada pasangan saya" (Nh, Perempuan, Wawancara, 16 Januari 2021).

Hatta juga berpendapat, bahwa jujur adalah bagian dari suara hati dan etika moralitas dalam menjaga perasaan sesama.(Hatta, 2010, hlm. 119-120) Sedangkan menurut Rochmawati, jujur atau kejujuran menjadi perihal yang patut dihargai dari seorang manusia, dengan kejujurannya akan mencerminkan dirinya menghargai orang lain dan takut berdusta (Rochmawati, 2018, hlm. 1-5). 


\section{2}

| TAZKIR: Jurnal Penelitian Ilmu-ilmu Sosial dan Keislaman

Vol. 07 No. 2 Desember 2021

\section{Kurangnya Komunikasi}

Dalam hubungan pacaran, komunikasi sangatlah penting. Komunikasi juga berimbas sebagai melanggengkan hubungan dan menjauhkan spekulasi negatif yang terbangun dalam benak-benak pikiran masing-masing. Dengan komunikasi akan saling memberi kabar dan hal positif lainnya demi melanggengkan hubungan. Di mana komunikasi sebagai bagian dari interaksi antar individu, begitupun hubungan pacaran, akan menjadi bagian interaksi antara laki-laki dan perempuan yang sedang menjalani hubungan pacarannya.

Oleh karena itu, komunikasi sangat penting dalma kehidupan sosial begitu dalam hubungan pacaran. Komunikasi dapat membangun dan mengintegrasikan individu, meski tidak saling bertatap muka atau menyentuh tapi dengan komunikasi bisa membangun integrasi satu sama lain. Komunikasi berarti saling kontak dan menyambung. Menurut Davis yang dikutip oleh Soekanto, kontak berasal dari bahasa latin yakni con artinya bersama-sama dan cum berarti menyentuh. Berarti kontak atau komunikasi dapat menyambungkan individu dengan individu yang lain entah itu melalui media massa dan alat media lainnya (Soekanto, 2006, hlm. 58).

Menurut Bogardus yang dikutip oleh Soekanto, komunikasi sebagai jalan menyampaikan sikap dan perasaan kepada orang yang diajak berkomunikasi. Komunikasi bisa membangun kedekatan antara perorangan. Selain itu dengan komunikasi sebagai interaksi yang membangun kedekatan dan konektifitas antar sesama (Soekanto, 2006, hlm. 61).

Sehingga komunikasi dalam hubungan pacaran juga sangat penting atau eksplisit. Namun dengan lemahnya komunikasi juga akan berdampak pada lemahnya harmonisme hubungan pacaran. Fenomena remaja pacaran di Desa Pandan Indah juga bahwasannya kerap kali terjadi hal tersebut, seorang pasangan yang jarang memberikan komunikasi atau memberi kabar pada pasanganya akan membuat pacarnya menjadi bimbang dan merasakan kegalauan. Sehingga kadang membangun spekulasi bahwa pacarnya tidak punya rasa sayang seperti biasanya, pacarnya selingkuh dan hal-hal negatif lainnya yang tersirat dalam benak-benak fikiran maupun batin ( $\mathrm{NH}$, Perempuan, Wawancara , 16 Januari 2021). 


\section{Pasangan yang Selingkuh}

Hal yang sering terjadi dalam hubungan pacaran juga yakni perselingkuhan. Selingkuh berarti kurangnya komitmen dari salah satu pasangan yang menjalin hubungan pacaran. Secara terminologi komitmen berarti bentuk kasih sayang dan kesetiaan yang terbangun begitu kuat agar tidak menyebabkan keterpurukan dalam hubungan yang dibina.(Ulwan, 2015, hlm. 89-90) Komitmen juga menjadi resistensi agar tidak terjadinya perselingkuhan.

Selingkuh berarti antonim dari kesetiaan. Kesetiaan merupakan bentuk ketulusan dalam membangun hubungan dan menjaganya dengan baik. Sehingga dengan setia maka setidaknya dapat menjadi bentuk menjaga kehormatan hubungan dan perasaan pasangan agar tidak terjadinya perselingkuhan diantara keduanya. Karena setia berarti komitmen yang senantiasa sangat diinginkan oleh orang yang sedang menjalani hubungan pacaran (Liana, 2017, hlm. 88).

Sehingga selingkuh adalah penyebab kegalauan yang terjadi pada hubungan pacaran. Pasangan yang selingkuh sagat membuat hati atau perasaan menjadi tak terkendalikan. Bahkan dengan terjadinya hubungan cinta segi tiga akan membuat rasa stress dan tidak ada spirit untuk menjalani hidup karena dampak kepikiran pasangan yang selingkuh dan membuat diri seorang menjadi galau dan menyendiri dalam kamar (S, Perempuan, wawancara, 19 Januari 2021)

\section{Resistensi Kegalauan Pada Remaja Pacaran Di Desa Pandan Indah Kecamatan Praya Barat Daya Kabupaten Lombok Tengah}

Kegalauan yang dirasakan oleh seseorang sedang menjalani hubungan pacaran memang beragam faktor penyebabnya misalnya pasangan yang selingkuh. Menurut Christiani, seingkuh atau pertengkaran dalam hubungan pacaran akan menyebabkan kekerasan secara sikis. Pasangan yang selingkuh akan menyebabkan hubungan menjadi retak dan mengakibatkan rasa galau, stress dan seperti halnya bisa saja akan terjadi cacat secara sikis (Devi, 2013, hlm. 2). Rasa galau memang kerap kali dirasakan pada orang yang sedang menjalai hubungan, terlebih-lebih ketika sudah merasakan begitu besarnya perasaan yang ternaman dan sudah siap untuk komitmen dalam hubungan yang dijalankan (Putri, 2010, hlm. 14).

Sehingga ketika merasakan putus cinta atau bertengkar dengan pasangannya, maka rasa galau akan rentan muncul dan merasuki perasaan batin. Di bawah ini ada beberapa faktor yang menjadi resistensi rasa galau yang 


\section{4 | TAZKIR: Jurnal Penelitian Ilmu-ilmu Sosial dan Keislaman}

Vol. 07 No. 2 Desember 2021

dilakukan oleh remaja pacaran di Desa Pandan Indah Kecamatan Praya Barat Daya Kabupaten Lombok Tengah yakni.

\section{Menenangkan diri di dalam kamar}

Menenangkan diri di dalam kamar adalah hal yang biasa atau lazim terjadi pada seorang perempuan yang skait hati akibat pasangannya. Dalam hal ini, ia lebih ke hal-hal dramatis menangis, di mana perempuan makhluk Tuhan yang super intuitif dan sangat berperasaan. Sehingga sangat rentan merasakan sakit hati, galau atau pun cemburu. Sehingga dalam hal ini, untuk melawan rasa galau yang cenderung dirasakan yakni dengan mematikan telepon dan menenangkan diri dalam kamar sebagai resistensi untuk menghilangkan rasa sakit hati, rasa sedih atau galau akibat hancurnya hubungan dengan pasangannya.

"Karena ketika saya mengalami putus cinta dengan pasangan saya, bahwa jika pasangann saya masih memiliki perasaan yang senantiasa inginn membujuk saya untuk kembali membangun hubungan dengannya, maka saya seakan-akan memastikan secara definitif terlebih dahulu, apa alasan pasangan saya untuk memilih putus dengan saya. Sedangkan saya sebagai seorang perempuan hendak hendak membangun inisaisi bahwa saya tidak segampang itu untuk memberikan ruang atau kesempatan ke dua, disebabkan saya telah terlanjur sakit hati dan merasakan dia begitu saja mempermainkan saya sebagai seorang perempuan".( Am, Perempuan, Wawancara, 16 Januari 2021)

\section{Mendengar musik dan Meningkatkan spiritualitas}

Menurut Plato musik akan menanamkan perrasaan yang damai dalam jiwa manusia. Dengan musik, maka manusia akan merasakna damai dan merasakan harmoni pada batinnya (Mahfud, 2009, hlm. 23). Oleh karena itu, jika batin atau hati sedang tidak stabil akibat hubungan pacaran, tentu dengan mendengar musik akan menjadi resistensi yang efektif pula dalam melawan perasaan sediih, kegalauan dan kerancuan pikiran akibat putus cinta dengan pasangannya.

Sehingga mendengar musik juga bagian dari alat atu resistensi dalam melawan dan menurunkan buruknya kondisi hati yang tidak optimal akobat putus cinta. Remaja pacaran di desa pandan indah juga melakukan hal 
sederhana seperti mendengar musik dalam melawan kondisi hati yang sedih, rasa galau akibat putus cinta atau hubungan pacarannya yang tidak lagi harmoni.

"Kalau saya galau gara-gara pacar. Hal yang sering saya lakukan yakni mendengar musik. Menurut saya mendengar musik adalah hal yang baik untuk menghilangkan rasa galau akibat bertengkar dengan pacar. Mendengar musik akan membuat diri saya menjadi fokus ke musik dan tidak mengingat tentang hubungan pacaran saya yang membuat saya galau". (S, Perempuan, wawancara, 19 Januari 2021)

"Sholat malam dan mengaji dengan tujuan agar perasaan membaik dan sebagai resistensi dalam melawan rasa galau atas hubungan pacarannya yang tidak stabil. Selain itu, dengan melakukan shalat malam dan mengaji, hati akan semakin damai dan tenang, agar ujian yang terjadi pada hubungan pacaran yang dijalankan untuk membuat dirinya semakin dewasa. Sehingga dengan jalan mengaji dan shalat juga bisa meminta yang lebih baik kepada Allah Swt. Terlebih-lebih saya sebagai seorang cewek yang lahir dalam didikan pendidikan agama atau pesantren, sehingga dengan shalat malam dan mengaji tentunya selalu menjadi resistensi atau cara dalam mengahadapi ujian, bahkan terkait dengan hubungan pacaran saya yang sama halnya membuat batin saya merasakan terpukul batin dan galau".( Nh, Perempuan, Wawancara, 16 Januari 2021)

\section{KESIMPULAN}

Penelitian ini mengkaji tentang penyebab dan resistensi kegalauan remaja pacaran di Desa Pandan Indah Kecamatan Praya Barat Daya Kabupaten Lombok Tengah. Oleh karena itu, seperti halnya kita tahu, pacaran sanga lazim kita dengar dan sangat terjadi pada anak-anak remaja maupun dewasa. Di mana pacaran sebagai proses menuju pernikahan entah di sisi lain pacaran juga menimbulkan kegaduhan secara internal dalam diri manusia akibat putus cinta bisa jadi ia merasakan kegalauan dan stress karena belum bisa mengontorl diri atas perasaannya. Di sini ada beberapa hal yang menyebabkan terjadinya kegaluan pada remaja pacaran di Desa Pandan Indah Kecamatan Praya Barat Daya Kabupetan Lombok Tengah yakni pasangan yang tidak jujur, kurangnya komunikasi dari pasangan, dan pasangan yang selingkuh (memiliki lebih dari satu 
pasangan). Oleh karena itu, hal-hal seperti mungkin terlihat sepele namun sangat berdampak serius pada batin atau perasaan seseorang, sehingga kadang menyebabkan kegalauan dan depressi atau stress. Namun di sisi faktor penyeybab kegalauan, ada beberapa hal yang dilakukan oleh remaja pacaran dalam melawan atau resistensi atas perasaan galanya yakni menenagnkan diri dengan mematikan ponsel, mengurung diri dalam kamar, jalan-jalan, melakukan perihal negatif yakni minuman keras, dan melakukan peribadatan seperti mengaji. 


\section{DAFTAR PUSTAKA}

Arisandi, H. (2015). Buku Pintar Tokoh-Tokoh Sosiologi Dari Klasik Sampai Modern. .Ircisod.

Ariyati, Rizki Ananda, \& Nuqul, Fathul Lubabin. (2016). Gaya Cinta (Love Style) Mahasiswa. Psikoislamika, Vol 13, No 2. http://ejournal.uinmalang.ac.id/index.php/psiko/article/view/6439

Darnoto, \& Triana Dewi, Hesty. (2020). Pergaulan Bebas Remaja Di Era Milenial Menurut Perspektif Pendidikan Agama Islam. Jurnal Tarbawi, Vol. 17 No. 2. https://ejournal.unisnu.ac.id/JPIT/article/view/1189

Devi, C. Noviolieta. (2013). Kekerasan Dalam Pacaran (Studi Kasus Pada Mahasiswa Yang Pernah Melakukan Kekerasan Dalam Pacaran). Program Studi Bimbingan Dan Konseling Jurusan Psikologi Pendidikan Dan Bimbingan Fakultas Ilmu Pendidikan Universitas Negeri Yogyakarta.

Efendi, Irwan. (2018). Kekerasan Dalam Berpacaran (Studi Pada Siswa SMAN 4 Bombang). Neo Societal, Vol 3, No 2.

Feist, Jess, Feist, George J., \& Roberts, Tommi-A. (2017). Theories Of Personality. Salemba Humanika.

Gunarsa, S. (2004). Psikologi Untuk Muda-Mudi. PT BPK Gunung Mulia,.

Hamsun, M. Y., \& Aminullah, A. (2017). Tradisi Kakwin Culik Masyarakat Suku Sasak Di Lombok Tengah Dalam Perspektif Komunikasi Budaya. Jisip; Jurnal Ilmu Sosial Dan Ilmu Politik, Vol 6, No 3. https://publikasi.unitri.ac.id/index.php/fisip/article/view/1465

Hatta, Ahmad. (2010). Tafsir Al-Qur'an Per Kata Surat At Tawbah. Magfirah Pustaka.

Imaningtyas, Intan, Atmoko, Adi, \& Triyono. (2017). Pengekspresian Jatuh Cinta Siswa Sekolah Menengah Pertama Melalui Media Tulisan: Kreativitas Atau Vandalisme. Jurnal Kajian Bimbingan Dan Konseling, Vol 2, No 4. http://journal2.um.ac.id/index.php/jkbk/article/view/842

Indriastuti, Ira, \& Nawangsari, Nur Aini Fardana. (2014). Perbedaan Cinta (Intimacy, Comitmen, Passion) Di Tinjau Dari Lamanya Perkawinan Istri Yang Sudah Bekerja. Jurnal Psikologi Dan Industri, Vol 3, No 3.

Liana, Jessica Ayu. (2017). Hubungan Antara Intensitas Komunikasi Dengan Komitmen Pada Pasangan Yang Menjalani Hubungan Berpacaran. 
Vol. 07 No. 2 Desember 2021

Jurnal Psikologi Udayana, Volume 4 Nomor 1. https://ojs.unud.ac.id/index.php/psikologi/article/download/30009/18 424

Lubis, A. Akhbar Abaibmas Rabbani. (T.T.). Nikah Mut'ah. Istinbath:Jurnal Hukum Dan Ekonomi Islam, Volume 19 Nomor 1.

Mahfud, Khoirul. (2009). 39 Tokoh Politik Sosiologi Dunia. Jaring Pena.

Parman, Lalu Gede. (1995). Kitab Adat Sasak Dulang 1 Perkawinan. CV Agung Perdana.

Putri, Angelia Sun. (2010). Cinta Dan Orientasi Masa Depan Romantis Pada Dewasa Muda Yang Berpacaran. Fakultas Psikologi Strata 1 Reguler.

Rochmawati, Nikmah. (2018). Peran Guru dan Orang Tum Membentuk Karakter Jujur Pada Anak. Jurnal Studi Dan Penelitian Pendidikan Islam, Volume 1, Nomor $2 . \quad$ lppmunissula.com/jurnal.unissula.ac.id/index.php/fikri/article/view/3203

Soekanto, S. (2006). Sosiologi Suatu Pengantar. Rajawali Pers,.

Ulwan, A. Nashih. (2015). Tarbiyatul Aulud Pendidikan Anak Dalam Islam. Khatulistiwa.

Zuhdi, Dkk, Muhammad Harfin. (2011). Lombok Mirah Sasak Adi. Imsak Press. 